\title{
The Design of Washer and Dryer Machine for Chopped Plastic Bottle
}

\author{
Kuni Nadliroh ${ }^{1}$, Fatkhur Rohman ${ }^{2}$ \\ \{kuninadliroh@unpkediri.ac.id ${ }^{1}$, fatkurrohman@ unpkediri.ac.id² ${ }^{2}$ \\ Universitas Nusantara PGRI Kediri, Kediri, Indonesia
}

\begin{abstract}
Plastic bottle waste is a type of waste that is increasing in volume every day, this is due to the prevalence of bottled drinks being marketed, how can almost everyone produce one used plastic bottle a day, this results in more and more plastic bottle waste, if not immediately handled then it will be bad especially for the environment. Lately, collectors of plastic bottle waste have appeared but they do not immediately process the plastic bottle, so the selling price of used plastic bottle is cheap, to increase the selling value of used plastic bottles, the used plastic bottle are processed by chopping so that it increases the selling value of the plastic bottles. Here will be explained about the design of plastic bottle washers and dryers that can be operated with a sample capacity of $5 \mathrm{~kg}$.
\end{abstract}

Keywords - Bottle; washer;dryer; plastic

Abstrak. Sampah botol plastik merupakan salah satu jenis sampah yang semakin hari semakin bertambah volumenya, hal ini dikarenakan maraknya minuman botol yang dipasarkan, bagaimana tidak hampir setiap orang dalam sehari menghasilkan botol plastik bekas satu botol, hal tersebut mengakibatkan sampah botol plastik yang semakin banyak, jika tidak segera ditangani maka hal tersebut akan berdampak buruk khususnya untuk lingkungan. Belakangan ini bermunculan pengepul sampah botol plastik akan tetapi mereka tidak langsung mengolah botol plastik tersebut, sehingga harga jual botol plastik bekas tersebut murah, untuk meningkatkan nilai jual botol plastik bekas maka botol plastik bekas tersebut diolah dengan cara dicacah sehingga meningkatkan nilai jual dari botol plastik tersebut. Disini akan dipaparkan mengenai desain pencuci dan pengering cacahan botol plastik yang bisa dioperasikan dengan kapasitas sampel $5 \mathrm{~kg}$.

Kata Kunci-botol; pencuci; pengering; plastik

\section{Pendahuluan}

Plastik merupakan bahan polimer sintesis yang dibuat melalui proses polimerisasi dimana tidak dapat lepas dari kehidupan kita sehari-hari yang umumnya kita jumpai dalam bentuk plastik kemasan ataupun penggunaannya pada alat-alat listrik dan peralatan rumah tangga. Sifatnya yang sulit terdegradasi di alam menjadikannya penyumbang limbah terbesaryang menyebabkan rusaknya keseimbangan alam.

Plastik berdasarkan kegunaannya dan pertimbangan ekonomis, plastik dibagi menjadi dua klasifikasi utama : plastik komoditi dan plastik teknik. Plastik komoditi dicirikan oleh volumenya yang tinggi dan harga yang murah. Mereka sering dipakai dalam bentuk barang yang bersifat pakai buang seperti lapisan pengemas, namun ditemukan juga pemakaiannya dalam barang-barang yang tahan lama. Beberapa contoh jenis plastik komoditi serta penggunaannya antara lain : LDPE (low density polyethylene) sebagai lapisan pengemas, isolasi kawat dan kabel, barang mainan, botol fleksibel, HDPE (high density polyethylene) digunakan sebagai botol, drum, pipa saluran, lembaran, film, issebolasi kawat dan kabel, PP (polyprophylene) digunakan sebagai bagian dan perkakas mobil, tali, anyaman, karpet, PVC (poly vynil chloride) digunakan sebagai bahan bangunan, pipa, bahan untuk lantai dan PS (poly styrene) digunakan sebagai bahan pengemas (busa dan film), perkakas, perabotan rumah dan barang mainan[1].

Plastik merupakan polimer sintesis yang bersifat sulit terurai di alam. Untuk dapat terurai secara sempurna dibutuhkan waktu hampir ratusan tahun. Bila dibandingkan antara penggunaan plastik yang terus meningkat terhadap waktu yang dibutuhkan untuk terurai tentu sudah dapat dibayangkan bagaimana dampak penumpukan limbah plastik pada lingkungan. Sampah kantong plastik ini bisa mencapai 400 ton setiap harinya atau setara dengan 16 pesawat Boeing 747. Program Lingkungan PBB bulan Juni 2006 mencatat setidaknya terdapat 46.000 sampah plastik di lautan setiap mil persegi. Bahkan diketahui arus pengumpulan sampah plastik ini membentuk pulau plastik yang terapung hampir mencapai dua kali luas pulau Kalimantan, Indonesia. Sampah plastik yang terbawa arus laut dapat mencemari biota laut, bahkan menimbulkan kematian pada hewan-hewan laut. Kematian sejumlah hewan laut sekitar satu juta burung laut, seratus ribu mamalia laut, serta ikan-ikan dikarenakan mengkonsumsi limbah plastik. Di darat, tanah yang mengandung racun partikel plastik dapat membunuh hewan pengurai, seperti cacing yang berakibat menurunkan tingkat kesuburan tanah. Sampah yang menumpuk di sungai dapat menimbulkan pendangkalan dan penyumbatan aliran sungai, sehingga banjir pun terjadi[2].

Nafakah, dalam penelitiannya yang berjudul desain dan analisis mesin pencuci cacahan botol plastik untuk industri kecil dengan menggunakan simulasi penelitian ini bertujuan untuk membuat desain, analisa, dan simulasi poros dan baling pada mesin pencuci cacahan botol plastik untuk industri kecil, Selain itu juga untuk mengetahui nilai yield strength dan nilai von mises maksimal dari material yang digunakan pada poros dan baling sehingga didapatkan Safety 
Faktor untuk mengetahui aman atau tidaknya material yang digunakan. Hasil analisa dan simulasi pada poros dan baling pada mesin cacahan botol plastik adalah $\left(282.685 .056 \mathrm{~N} / \mathrm{mm}^{2}\right)$, sedangkan nilai tegangan von mises maksimal dari material pada poros adalah $149.080 .416 \mathrm{~N} / \mathrm{mm}^{2}$.

Selanjutnya adalah penelitian yang membahas tentang alat untuk memproses limbah plastik yang juga di lakukan oleh Engki dan suryadhi. Dalam penelitiannya yang berjudul rancang bangun mesin pengering sentrifugal pada proses penggilingan sampah pastik jenis polyethylene therephthalate (PET). Penelitian ini bertujuan untuk mengimplementasikan teori gaya sentrifugal dan gaya gravitasi dalam alat sentris pengering plastik (centrifugal dryer) sehingga dapat dihasilkan suatu mesin pengering sentrifugal. Metode yang dipakai dalam pembuatan mesin pengering sentrifugal adalah dengan memanfaatkan azas gaya sentrifugal dan gaya gravitasi. Hasilnya diperoleh suatu mesin pengering yang mampu bekerja dan menghasilkan $2.880 \mathrm{~kg}$ selama satu hari (8 jam) [3].

Lebih lanjut lagi juga merupakan sebuah judul penelitian yang juga membahas tentang sistem pengolahan limbah plastik pada penelitian yang di lakukan oleh Sahwan. Dalam penelitiannya yang berjudul :Sistim pengolahan limbah plastik di indonesia. Penelitian ini menjelaskan tentang jalur tata niaga limbah plastik hingga proses pendauran ulangan yang meliputi pencacahan, pencucian, pengeringan, hingga akhirnya limbah plastik di cetak menjadi produk yang di inginkan. Hasilnya diperoleh alat ini mampu menghasilkan cacahan botol plastik $50 \mathrm{~kg} / \mathrm{jam}$ [4].

\section{METODE}

\section{A. Pengumpulan data}

Tahapan awal adalah melakukan pengumpulan data dengan tujuan untuk merangkum teori-teori dasar, acuan secara umum dan khusus, serta untuk memperoleh berbagai informasi pendukung lainnya yang berhubungan dengan pengerjaan Perancangan Mesin ini. Untuk pengumpulan data ini diperoleh dengan cara:

\section{Studi literatur}

Yaitu mencari buku-buku yang berhubungan dengan proses penelitian dan jurnal-jurnal penelitian yang berhubungan dengan penelitian ini yang dilakukan di perpustakaan atau melalui internet. Studi literatur juga dimaksudkan untuk memperoleh gambaran secara lebih detail mengenai perancangan mesin pencuci dan pengering cacahan botol plastik.

\section{Observasi}

Selain itu pengumpulan data ini juga bisa dilakukan dengan cara observasi lapangan langsung. Yaitu dengan cara datang ke industri pengolahan limbah plastik. Untuk melihat proses daur ulang limbah plastik. Serta observasi juga dilakukan di toko untuk mengetahui ukuran dari bahan agar ukuran yang kita perlukan untuk mesin sesungguhnya sesuai dengan ukuran yang ada di toko. Setelah melakukan studi literatur dan observasi di lanjutkan ke proses pengolahan data. Data-data yang telah didapatkan selanjutnya diolah dalam bentuk proposal. Dalam proposal ini Penulis memasukkan data-data yang dianggap perlu dan menunjang dalam proses perancangan mesin ini.

\section{B. Perancangan}

Pada tahap ini dilakukan pemodelan sistem dari data yang sudah ada dari hasil pengumpulan data sehingga datatersebut dapat dijadikan acuan dalam proses berikutnya. Perancangan alat ini terlebih dahulu membuat gambar model melalui softwer inventor atau dalam bentuk gambar lainnya lalu sampai akhirnya kita akan mendapatkan hasilsimulasinya. Selanjutnya masuk tahap penentuan bahan dalam tentang cara pembuatan komponen-komponen alat dan pembelian komponen yang di butuhkan dalam pembuatan alat.

\section{Pengujian alat}

Pada tahap ini dilakukannya proses penghitungan untuk menentukan kekuatan dari bahan yang digunakan. Dalam proses ini banyak digunakan rumus-rumus untuk mendukung proses perhitungan agar tidak salah saat menghitung setiap kekuatan bahan. Jika tidak sesuai dengan kebutuhan yang telah ditentukan maka harus mengulang dari diagram alir yang telah dibuat.

\section{Pembuatan laporan akhir}

Pada tahap ini akan dilakukan pembuatan laporan yang telah selesai dan proses perhitungan yang telah sesuai dengan kebutuhan proses pembuatan alat. 


\section{HaSil dan PembahaSan}

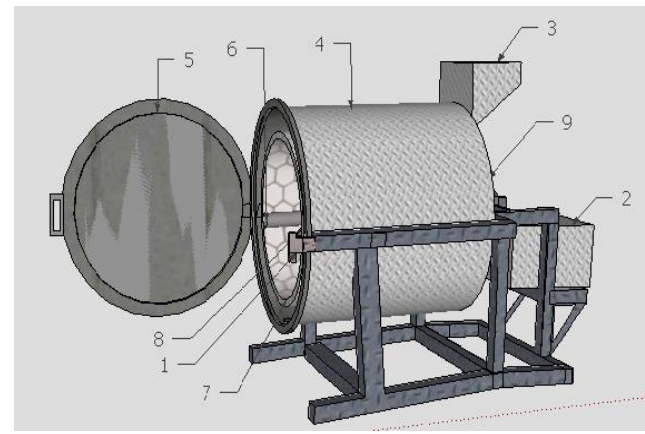

Gambar 1. Alat pencuci dan pengering cacahan botol plastik.

1. Pengunci tutup

2. Motor listrik

3. Corong masuk

4. Chasing

5. Tutup chasing

6. Poros pengaduk

7. Screen

8. Sudu pengaduk

9. Puli dan V-belt

Berikut ini adalah gambar desain alat dari berbagai sudut pandang yang meliputi : Gambar alat pencuci dan pengering botol plastik tampak dari depan.

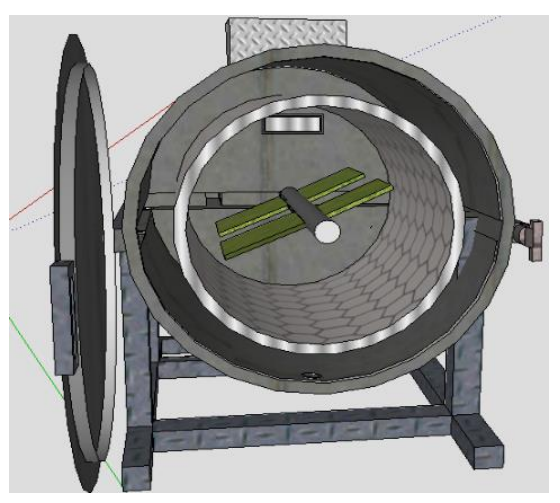

Gambar 2. Gambar alat dari depan

Gambar alat pencuci dan pengering cacahan botol plastik tampak dari atas.

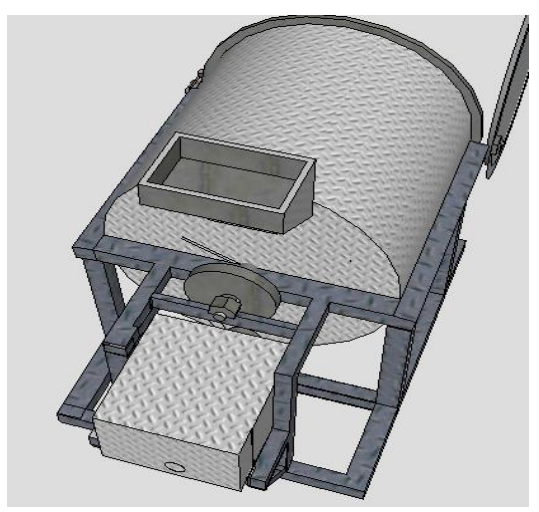


Gambar 3. Gambar alat dari atas

Gambar alat pencuci dan pengering cacahan botol plastik beserta dimensinya.

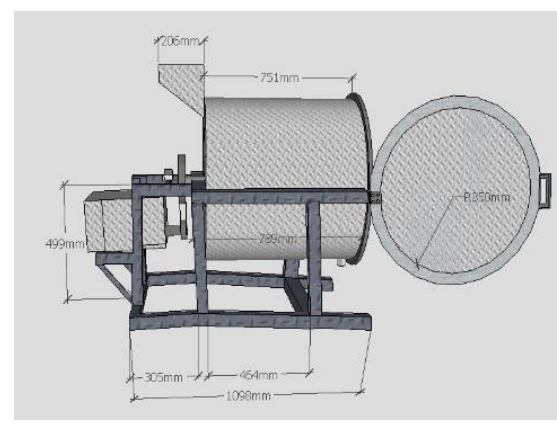

Gambar 4. Gambar dimensi alat

Dalam perancangan ini harus melalui validasi alat yang di lakukan oleh ahli dari pakar pendidikan dan pakar industri unuk mengetahui alat layak di gunakan atau tidak. Berikut adalah hasil dari validasi alat yang sudah di lakukan :

\section{Hasil validasi pakar industri}

Dari segi desain alat ini cukup bagus dan memiliki nilai estetika, tapi dari segi keamanan masih sangat kurang karena alat ini berhubungan dengan air sedangkan mesin ini banyak kompenenya yang terbuat dari besi jadi sangat berbahaya apabila terjadi konsleting. Untuk kompenen mesin terutama penggeraknya, daya yang di hasilkan masih kurang untuk memutar poros dengan kecepatan tinggi tetapi untuk kompenen pendukung seperti rangka, casing, dan penyambungannya cukup baik.

Sedangkan dari aspek kinerja kesesuaian produk dengan desain sudah baik, tetapi dari getaran dan kebisingan masih kurang karena tingkat getaran yang dihasilkan masih terlalu besar. Untuk kualitas bahan baku dan ukuran sudah sesuai dengan desain awal, serta perawatan alat sangat mudah. Pada perancangan alat ini tentunya juga berpedoman pada ilmu elemen mesin. Merupakan ilmu yang mempelajari bagian-bagian mesin dilihat antara lain dari sisi bentuk komponen, cara kerja, cara perancangan dan perhitungan kekuatan dari kompenen tersebut. Pada validasi ini validator memberi saran dan komentar bahwa alat ini lumayan baik, tetapi putaran mesin saat mencuci dan mengeringkan sebaiknya di buat berbeda, karena saat proses pencucian putaran mesin terlalu cepat. Dari hasil penilaian yang diberikan, mesin /alat tersebut telah layak untuk digunakan dengan syarat perbaikan.

\section{Hasil validasi pakar pendidikan}

Dari penilaian yang sudah lakuan oleh validator di berbagai aspek yang dinilai mulai segi desain, komponen mesin, kinerja, kualitas, layanan after sales, hingga limbah dapat di jelaskan sebagai berikut :

Dari segi desain Indikator penilain yang dinilai meliputi nilai Estetika mendadapatkan hasil kurang, Ergonomis memperoleh nilai yang kurang, dan pada keamanan alat dinilai kurang karena masih adanya perbaikan. Sedangkan penilaian pada komponen mesin meliputi Penggerak utama dinilai baik untuk sebuah alat pencuci dan pengering, Sistem Transmisi (Pemindah Tenaga) pada alat ini dinilai cukup karena sistem pemindah sudah satu rangkaian motor pengerak. Rangka mendapat hasil penilaian baik, Casing yang digunakan pada alat ini dinilai cukup oleh validator, dan lalu komponen penyambung mendapat penilain kurang.

Dari sisi kinerja indikator penilaian yang dilakukan pada kesuaian produk dengan desain dinilai kurang, lalu penilain pada getaran dan kebisingan dinilai kurang karena motor yang digunakan kurang stabil rpmnya. Sedangkan kualitas penilaian yang dilakukan dari segi ini meliputi Kesesuaian ukuran dengan bahan baku dinilai kurang karena ukuran kenyataanya tidak sesuai dengan desain, dan juga kondisi bahan baku dinilai kurang. Kehandalan produk dinilai kurang dikarenakan masih perlu adanya sedikit perbaikan pada alat.

Dari segi layanan after sales penilaian yang dilakukan meliputi aspek Ketersediaan komponen di pasaran mendapatkan nilai kurang, dan juga Kemudahan dalam service dinilai kurang. Sedangkan untuk Limbah penilaian yang dilakukan yaitu bahan yang sudah tidak terpakai bisa direuse dan recycle kembali mendapatkan nilai baik karena kebanyakan bahan terbuat dari besi yang sulit diuraikan. Setelah perancangan di lakukan maka uji coba di lakukan dalam beberapa kali. Pada hasil percobaan model peraga alat pencuci dan pengering cacahan botol plastik di beri beban yang berbeda-beda. Berikut adalah tabel hasil uji coba yang sudah di lakukan : 
Dari hasil uji coba yang sudah di lakukan di ketahui rata-rata alat mampu menghasilkan $0,729 \mathrm{~kg} / \mathrm{menit}$ dalam sekali proses. Untuk dapat memperoleh nilai angka $0,729 \mathrm{~kg} / \mathrm{menit}$ di pengaruhi oleh :
1. Daya motor : $9,536 \mathrm{~kW}$
: $12,788 \mathrm{HP}$
Keterangan : $1 \mathrm{~kW}$ setara dengan 1,34 HP
2. Poros : $: 38400 \mathrm{~N} / \mathrm{mm}^{2}$
3. Torsi : $1200 \mathrm{Nmm}$
4. Pasak :
Lebar pasak $: 15 \mathrm{~mm}$
Tebal pasak : $10 \mathrm{~mm}$
Panjang pasak : 47,1 mm

Tabel 1. Hasil Uji Coba

\begin{tabular}{ccc}
\hline No & $\begin{array}{c}\text { Berat } \\
\text { (kg) }\end{array}$ & $\begin{array}{c}\text { Waktu } \\
\text { (menit) }\end{array}$ \\
\hline 1 & 1 & $01: 36,4$ \\
\hline 2 & 2 & $03: 08,1$ \\
\hline 3 & 3 & $04: 11,3$ \\
\hline 4 & 4 & $06: 13,7$ \\
\hline 5 & 5 & $07: 42,4$ \\
\hline
\end{tabular}

\section{KESIMPULAN}

Berdasarkan hasil perancangan yang telah di uraikan di bab sebelumnya, maka telah dihasilkan perancangan alat pencuci dan pengering cacahan botol plastik kapasitas $5 \mathrm{~kg}$ dengan spesifikasi sebagai berikut, daya yang di hasilkan motor sebesar $12,788 \mathrm{Hp}$, serta poros yang di gunakan adalah besi st 37dengan panjang poros $70 \mathrm{~cm}$ dan torsinya 1200 $\mathrm{N} / \mathrm{mm}$. Tegangan puntir pada poros sebesar $38400 \mathrm{~N} / \mathrm{mm}$, dengan ukuran pasak 47,1 mm x $15 \mathrm{~mm}$ dan ketebalan 10 $\mathrm{mm}$. Sedangkan tabung pencuci dengan diameter tabung $40 \mathrm{~cm}$ tebuat dari bahan plat setebal $3 \mathrm{~mm}$ dengan kemiringan $20^{\circ}$, rangaka alat terbuat dari besi hollow $3 \times 3 \mathrm{~cm}$.

\section{REFERENSI}

[1] Nasution, S Reni. 2015. “ Berbagai Cara Penanggulangan Limbah Plastik. ” Journal of Islamic Science and Technology. I. 1, 97-104.

[2] Karo, Uli. dan Suartini, Tuti. 2010. “Analisis sampah Berjenis Sampah Plastik untuk Meningkatkan Pendapatan Msyarakat di Areal tempat Pembuangan Akhir (TPA).” Penelitian Pendidikan. VIII. 2.

[3] Krisnarti, A Engki dan Suryadhi. 2015. “Rancang Bangun Mesin Pengering Sentrifugal Pada Proses Proses Sampah Plastik Jenis Polyethylene Therephthalate (PET)”. Jurnal Sains dan Teknologi. 10. 1, 68-77.

[4] Sahwan. F. L. dkk. 2015. Sistem Pengolahan Limbah Plastik Di Indonesia. Journal. Tek. Ling. P3 TL-BPPT. 6. (1) : 311-318 